\title{
Pulse: Revived in 'The Pulse of Asia'
}

\author{
Jeong Bae Park ${ }^{a}$ Michael F. O'Rourke ${ }^{b}$ Hiromichi Suzukic \\ aDivision of Cardiology, Cheil General Hospital, Kwandong University College of Medicine, \\ Seoul, South Korea; bSt Vincent's Clinic, Victor Chang Cardiac Research Institute and \\ University of New South Wales, Sydney, N.S.W., Australia; 'Department of Nephrology, \\ Community Health Science Center, Irumagun, Japan
}

Blood flow in arteries is pulsatile, and palpating arterial pulse has a long history and is full of brilliant surprises. The finding that very ancient physicians applied this technique when diagnosing and treating sick people dates back to $600 \mathrm{BC}$ in Eastern countries. It is thought that arterial pulse was first mentioned in the 'Classic of Internal Medicine' Nei Ching written by the Yellow Emperor Huang Ti (698-598 BC) in the same period of time [1]. Ancient Asian physicians in China, Korea, and other countries developed the ability and techniques of feeling the arterial pulse and treated patients by using them. When it comes to the techniques, the examination was performed by feeling the pulses on both wrists, which has three parts: cun, guan, and chi [2] (fig. 1). The Egyptians' notion of the pulse is similar to or older than that of Eastern Asia. As shown in the 'Edwin Smith Papyrus' (1600 BC), 'The Therapeutic Papyrus of Thebes' (1552 BC), and the 'Ebers Papyrus' (1550 BC) [3], ancient Egyptians as well treated

Fig. 1. Pulse diagnosis using three fingers at the radial artery: cun, guan, and chi.

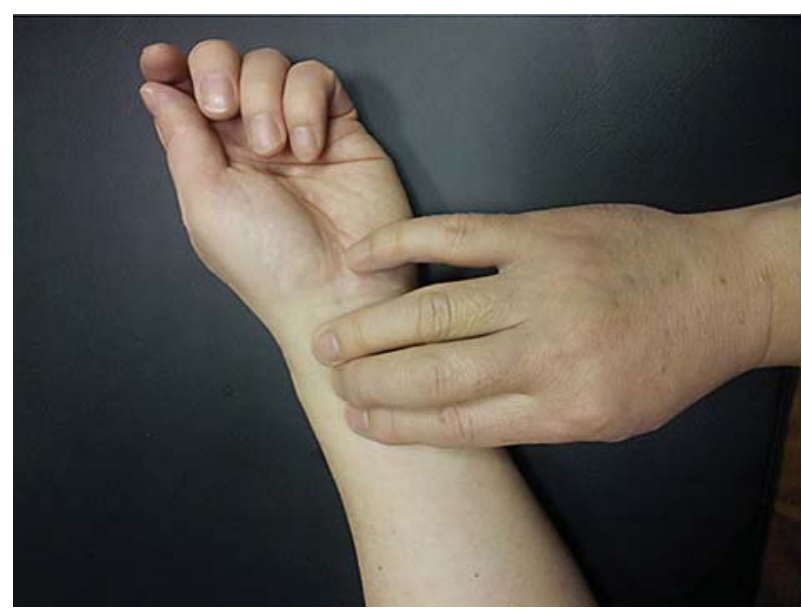




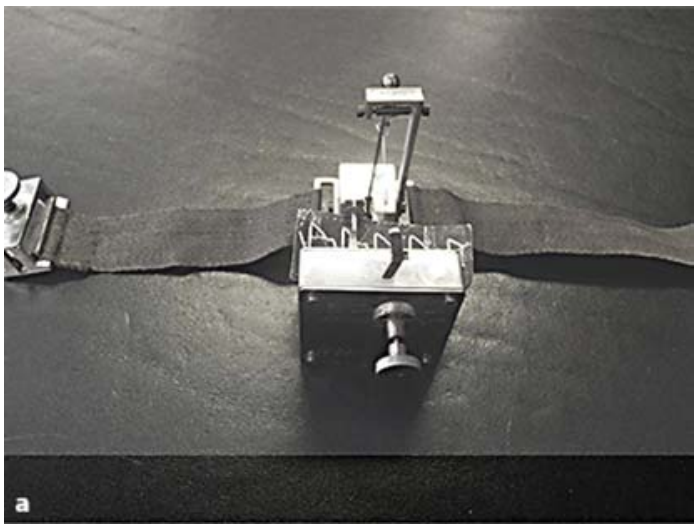

Fig. 2. a Sphygmograph device. b Application of the device shown in a on the wrist. $\mathbf{c}$ Graphic depiction of the arterial wave from a case with large, tortuous, and atheromatous arteries.
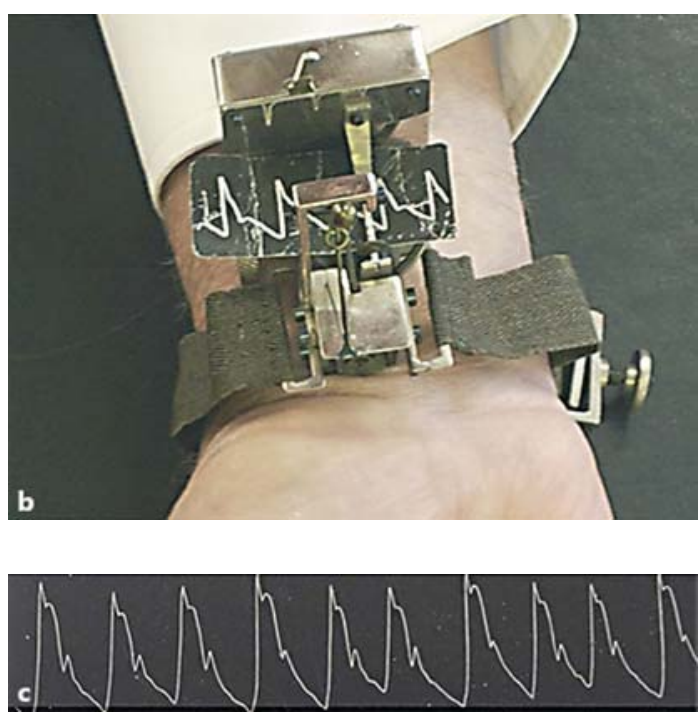

the sick by feeling the pulse using fingers and hands. In ancient Indian medicine (600 BC), physicians diagnosed and treated the sick using pulse examination in life medicine. Pulse diagnosis appeared in the West after the Middle Ages. In Greek medicine, Hippocrates (375 BC), Praxagoras of Kos (340 BC), and Erasistratus (304-250 BC) described the characteristics of the pulse and the understanding of circulation [4]. Thus, it is probable that physicians more than 2,500 or 2,600 years ago diagnosed and treated patients as well as clarified the prognosis through examination of the pulse and identification of pulse shapes both in the East and West.

In medieval medicine, physicians started to study pulse shapes and developed a device to determine pulse characteristics. This device, Hérrison's sphygmometer, was designed to examine the pulse in relation to its force, regularity, and rhythm. It is known to be the first to show the function of the arteries [5] and so enables physicians to assess the pulse with objective findings. Thereafter, many upgrades of this device were made by brilliant scientists, for example Carl Ludwig's Kymograph, Etienne Marey's sphygmograph, and Frederick Akbar Mahomed's sphygmograph, a revised form of Marey's sphygmograph. In personal and historical perspectives on Frederick Akbar Mahomed written by Michael F. O’Rourke [6], Mahomed cogently argued in it:

'The pulse, ranks the first among our guides; no surgeon can despise its counsel, no physician shut his ears to its appeal. Since, then, the information the pulse affords is of so great importance and so often consulted, surely it must be to our advantage to appreciate fully all it tells us, and to draw from it all that it is capable of imparting. Our sense of touch, however highly educated, is manifestly liable to error and it is to our more reliable sense, that of sight, we appeal, when possible, for confirmation. It is by the aid of this more accurate sense we should study the pulse in its marvellous changes of character and form, as recorded by the sphygmograph.'

The use of the arterial pulse in the history of medicine can be found from ancient times to the modern era, i.e. since 2,600-4,500 years. Scientific progress in arterial pulse examination continues at a faster pace than ever, with the advent of advanced technologies designed by marvelous clinical scientists and technical inventors. Therefore, there is a growing need to further develop and modernize the old-fashioned pulse-by-touch examination to make it more scientifically in tune with the time. Accordingly, a Society titled 'The Pulse of Asia' was founded, and its first meeting was held in Daegu, Korea, in 2009. Since then, regular annual 
meetings have been held in Tokyo, Japan, Beijing, China, and Sydney, Australia. The inaugural society meeting under the new name 'The Pulse of Asia Society' will be held in the year 2013. As a final product, the journal Pulse has been created. This journal will certainly help to grow and further our understanding of the arterial biology and physiology in diverse aspects in basic, clinical, and translational medicine. The journal Pulse accepts two kinds of review articles: (1) extensive literature overviews and (2) mini-reviews which provide overviews of recent key data and therapeutic regimens as well as editorials in the field of vascular research. Bringing together the basic and clinical sciences across a range of disciplines, Pulse provides a forum for communicating the latest findings and hypotheses that enhance our understanding of pulsatile processes and vascular disease. The transdisciplinary approach of the journal fosters collaboration in relevant areas including cardiology, nephrology, neurology, diabetes, general medicine, and gerontology.

We hope Pulse works well as a diligent and indefatigable pulse.

Jeong Bae Park, Seoul

Michael F. O'Rourke, Sidney

Hiromichi Suzuki, Irumagun

January 29, 2013

\section{References}

1 Ruskin A: Introduction; in Ruskin A (ed): Classics in Arterial Hypertension. Springfield, Charles C Thomas, 1956, p xi.

2 Dharmananda S: The significance of traditional pulse diagnosis in the modern practice of Chinese medicine. http://www.itmonline.org/arts/pulse.htm.

3 Naqvi NH, Blaufox MD: Blood Pressure Measurement: An Illustrated History. New York, The Parthenon Publishing Group, 1998.

4 Parker KH: A brief history of arterial wave mechanics. Med Biol Eng Comput 2009;47:111-118.

5 Hérisson J: The Sphygmometer, an Instrument Which Renders the Action of the Arteries Apparent to the Eye. London, Longman, Rees, Orme, Brown, Green, and Longman, 1835.

6 O’Rourke MF: Frederick Akbar Mahomed. Hypertension 1992;19:212-217. 